\title{
Effects of Sugars and Amino Acids on Sodium and Potassium Influx in Rabbit Ileum
}

\author{
Raymond A. Frizzell, Hugh N. Nellans, and Stanley G. Schultz \\ From the Department of Physiology, University of Pittsburgh School of \\ Medicine, Pittsburgh, Pennsylvania 15213
}

\section{INTRODUCTION}

There is compelling evidence that the presence of actively transported sugars or amino acids in the mucosal solution increases sodium absorption and the transmural electrical potential difference across a variety of in vitro and in vivo preparations of small intestine. The mechanism(s) underlying these effects is, however, unsettled. One possibility invokes a direct interaction between sodium and brush border carrier mechanisms for sugars and amino acids which results in an increased influx of sodium from the mucosal solution into the cell, across the mucosal membrane. This is then followed by active extrusion of sodium from the cell into the serosal solution or plasma (1). A second possibility has been suggested by Fordtran, Rector, and Carter (2) as a result of their studies on sodium absorption by human jejunum in vivo. These investigators have proposed that the increase in net sodium absorption observed in the presence of glucose or galactose may be the result of solvent drag, perhaps through tight junctions and the lateral intercellular spaces, secondary to the sugar-induced increase in water absorption. If this solvent drag pathway is cation-selective, the increase in transepithelial electrical potential difference could be attributed to a streaming potential. Needless to say, these proposed mechanisms are not mutually exclusive and may coexist; the contribution of one or both of these mechanisms to the enhancement of sodium absorption by glucose would be expected to vary with species, site of small intestine and whether in vivo or in vitro preparations are employed.

Recent studies by Frizzell and Schultz (3) have provided evidence for the presence of an extracellular transepithelial shunt pathway in rabbit ileum which is

Received for publication 25 August 1972 and in revised form 17 October 1972. cation selective and displays high partial ionic conductances for sodium and potassium. Evidence has been presented for a variety of low resistance epithelia that the anatomic counterpart of these extracellular transepithelial shunt pathways correspond to the tight junctions and the lateral intercellular spaces $(4,5)$. In addition, there appears to be widespread agreement that solutecoupled water flow traverses these lateral intercellular spaces $(6,7)$. Further, it seems likely that the "tight" junctions are permeable to water and water-soluble molecules that do not traverse cell membranes (e.g., sucrose) and that ions traverse this watery environment in their hydrated forms $(3,4,8,9)$ Thus, it seems likely that the "standing osmotic gradient" in the lateral interspaces (6) would draw water through the tight junctions which, in turn, could exert a solvent-drag effect on ions and other solutes to which the junctions are permeable. Thus, the extracellular shunt pathway described by Frizzell and Schultz could in principle fulfill all of the requirements for the model proposed by Fordtran et al. and it was, therefore, of interest to determine whether the enhanced sodium influx across the luminal surface of rabbit ileum elicited by actively transported sugars or amino acids (1) could be attributed to movement through this pathway in response to solvent-drag. Since the permeability of this shunt pathway to potassium is greater than that to sodium $\left(\mathrm{P}_{\mathrm{K}} / \mathrm{P}_{\mathrm{Na}}=1.14\right)$ the solvent-drag model would predict that the presence of sugars or amino acids in the mucosal solution would stimulate the unidirectional influx of potassium from the mucosal solution into the epithelium as well as the infux of sodium. In order to test this notion, simultaneous sodium and potassium influxes across the brush border of rabbit ileum have been determined in the presence and absence of three actively transported organic solutes, alanine, glucose, and galactose. 


\section{METHODS}

The techniques for the determination of solute influx across the luminal surface of rabbit ileum have been described (10). Briefly, the procedure involves exposure of defined areas of the mucosal surface of isolated segments of distal ileum to a mucosal test solution containing $\left[{ }^{22} \mathrm{Na}\right],\left[{ }^{42} \mathrm{~K}\right]$, and $\left[{ }^{3} \mathrm{H}\right]$ inulin for a brief period $(45 \mathrm{~s})$. The zero-time rate of uptake of tracer is calculated from the tracer content of the tissue after correction for the inulin space. Sodium and potassium influxes were determined simultaneously by assaying the tissue extract after $2 \mathrm{~h}$ of extraction and again after 2 wk when virtually all of the ${ }^{42} \mathrm{~K}$ had decayed. Areas of the mucosal surface were exposed to solutions containing alanine, glucose, or galactose and adjacent areas were exposed to solutions containing an isosmotic equivalent of mannitol. Most solutions contained $140 \mathrm{mM} \mathrm{Na}$ and $12 \mathrm{mM}$ $\mathrm{K}$, buffered to $\mathrm{pH} 7.4$ at $37^{\circ} \mathrm{C}(3)$. In experiments where alanine was present in the test solution, the sodium concentration was reduced to $70 \mathrm{mM}$ by replacement of $\mathrm{NaCl}$ with choline chloride; this concentration of sodium elicits a near maximal stimulation of alanine-dependent sodium influx while reducing the magnitude of the alanine-independent sodium influx so that the "signal-to-noise" ratio is increased (11).

\section{RESULTS AND DISCUSSION}

The effects of alanine $(20 \mathrm{mM})$, glucose $(10 \mathrm{mM})$, and galactose $(20 \mathrm{mM})$ on simultaneously determined sodium and potassium influxes are given in Table I. The values obtained for sodium and potassium influxes are in excellent agreement with individually determined values reported previously (3). Clearly, there is a significant stimulation of sodium influx in the presence of each actively transported solute; the enhanced influxes are in close agreement with those predicted from previous studies on the kinetics of coupled sodium-amino acid (11) and coupled sodium-sugar (12) influxes. In contrast, potassium influxes were unaffected by the presence of actively transported sugars or amino acids

TABLE I

Effects of Alanine, Glucose, and Galactose on Simultaneous $\mathrm{Na}$ and $\mathrm{K}$ Influxes*

\begin{tabular}{|c|c|c|}
\hline & $\mathrm{JNa}_{\mathrm{Na}}$ & $\mathrm{J}_{\mathrm{K}}$ \\
\hline & \multicolumn{2}{|c|}{$\mu \mathrm{mol} / \mathrm{cm}^{2}, h$} \\
\hline Control (16) & $10.7 \pm 0.8$ & $2.46 \pm 0.14$ \\
\hline \multirow[t]{2}{*}{$+20 \mathrm{mM}$ alanine $(16)$} & $13.5 \pm 1.0$ & $2.35 \pm 0.12$ \\
\hline & $P<0.05$ & $P>0.05$ \\
\hline Control (8) & $19.3 \pm 0.8$ & $2.31 \pm 0.19$ \\
\hline \multirow{2}{*}{$+10 \mathrm{mM}$ glucose $(8)$} & $22.4 \pm 0.8$ & $2.07 \pm 0.15$ \\
\hline & $P<0.05$ & $P>0.05$ \\
\hline Control (16) & $22.5 \pm 0.7$ & $2.41 \pm 0.08$ \\
\hline \multirow[t]{2}{*}{$+20 \mathrm{mM}$ galactose $(15)$} & $25.1 \pm 0.5$ & $2.47 \pm 0.08$ \\
\hline & $P<0.01$ & $P>0.05$ \\
\hline
\end{tabular}

* See text for details. Number of observations in parentheses; errors are SEM. in the mucosal solution; in no instance did influx in the presence of alanine, glucose, or galactose significantly differ from that observed in the presence of mannitol. In view of the differences in the sodium and potassium concentrations in the mucosal solution, the expected increase in potassium influx predicted by a solvent-drag model can be calculated from the observed increases in sodium influx, the ratio between sodium and potassium concentrations, and the ratio of sodium and potassium permeabilities of the shunt pathway. The predicted increases in potassium influx in the presence of $20 \mathrm{mM}$ alanine, $10 \mathrm{mM}$ glucose, and $20 \mathrm{mM}$ galactose are $0.5,0.3$, and $0.3 \mu \mathrm{mol} / \mathrm{cm}^{2}, \mathrm{~h}$, assuming that the frictional interaction between water flow and sodium and potassium does not differ markedly. The observed potassium influxes in the presence of alanine, glucose, and galactose differ significantly from those predicted on the basis of these assumptions $(P<0.01)$.

In summary, the data in Table I indicate that actively transported sugars or amino acids in the mucosal solution stimulate sodium influx but have no effect on potassium influx. In view of the fact that the shunt pathway is more permeable to the latter than to the former, these observations argue strongly against a mechanism of solvent drag, as an explanation for these observations and are consistent with the previous conclusions of Rose and Schultz (13), based on electrophysiological observations, that solute-coupled sodium influx traverses the mucosal membrane. An alternate explanation for these findings is that there are two shunt pathways, one that is permeable to water and sodium but impermeable to potassium, and another that is permeable to potassium and impermeable to water. This seems highly unlikely in view of the fact that the hydrated radius of potassium is smaller than that of sodium and the above cited evidence that ions traverse the shunt in their hydrated forms.

It should be stressed that the present observations do not exclude the possibility that during long-term experiments, either in vivo or in vitro, increased water absorption may enhance the absorption of ions and small water soluble molecules, either by means of solvent-drag or by molecular sieving which would increase local concentrations in the unstirred layer adjacent to the mucosal surface ( $c f .14$ ). In short, these observations do not exclude the possibility that increased water flow contributes to increased sodium absorption; on the other hand, they provide strong support for the notion that the increase in sodium influx across the luminal surface of rabbit ileum in the presence of actively transported sugars or amino acids cannot be attributed to solvent-drag through the extracellular shunt pathway that traverses this tissue. 


\section{ACKNOWLEDGMENTS}

This project was supported by research grants from the U. S. Public Health Service, National Institutes of Health (AM-13744) and the American Heart Association (70-633). Raymond A. Frizzell (AM-49585) and Hugh N. Nellans (AM-52248) were U. S. Public Health Service Postdoctoral Research Fellows and Stanley G. Schultz was the recipient of a Research Career Development Award from the National Institute of Arthritis and Metabolic Diseases (AM-9013).

\section{REFERENCES}

1. Schultz, S. G., and P. F. Curran. 1970. Coupled transport of sodium and organic solutes. Physiol. Rev. 50: 637.

2. Fordtran, J. S., F. C. Rector, Jr., and N. W. Carter. 1968. The mechanisms of sodium absorption in the human small intestine. J. Clin. Invest. 47: 884.

3. Frizzell, R. A., and S. G. Schultz. 1972. Ionic conductances of extracellular shunt pathway in rabbit ileum: Influence of shunt on transmural sodium transport and electrical potential differences. J. Gen. Physiol. 59: 318.

4. Frömter, E., and J. Diamond. 1972. Route of passive ion permeation in epithelia. Nat. New Biol. 235: 9.

5. Whittembury, G., and F. A. Rawlins. 1971. Evidence of a paracellular pathway for ion flow in the kidney proximal tubule: electronmicroscopic demonstration of lanthanum precipitate in the tight junction. Pflueg. Arch. $330: 302$.
6. Tormey, J. M., and J. M. Diamond. 1967. The ultrastructural route of fluid transport in rabbit gall bladder. J. Gen. Physiol. 50: 2031.

7. Tomasini, J. T., and W. O. Dobbins III. 1970. Intestinal mucosal morphology during water and electrolyte absorption. A light and electron microscopic study. Am. J. Dig. Dis. 15 : 226.

8. Smulders, A. P., J. McD. Tormey, and E. M. Wright. 1972. The effect of osmotically induced water flows on the permeability and ultrastructure of the rabbit gallbladder. J. Membrane Biol. 7 : 164.

9. Frömter, E. 1972. The route of passive ion movement through the epithelium of Necturus gallbladder. J. Membrane Biol. 8: 259.

10. Schultz, S. G., P. F. Curran, R. A. Chez, and R. E. Fuisz. 1967. Alanine and sodium fluxes across mucosal border of rabbit ileum. J. Gen. Physiol. 50: 1241.

11. Curran, P. F., S. G. Schultz, R. A. Chez, and R. E. Fuisz. 1967. Kinetic relations of the $\mathrm{Na}$-amino acid interaction at the mucosal border of intestine. J. Gen. Physiol. 50: 1261.

12. Goldner, A. M., S. G. Schultz, and P. F. Curran. 1969. Sodium and sugar fluxes across the mucosal border of rabbit ileum. J. Gen. Physiol. 53: 362.

13. Rose, R. C., and S. G. Schultz. 1971. Studies on the electrical potential profile across rabbit ileum: effects of sugars and amino acids on transmural and transmucosal electrical potential differences. J. Gen. Physiol. 57: 639.

14. Wedner, H. J., and J. M. Diamond. 1969. Contributions of unstirred-layer effects to apparent electrokinetic phenomena in the gall bladder. J. Membrane Biol. 1: 92. 